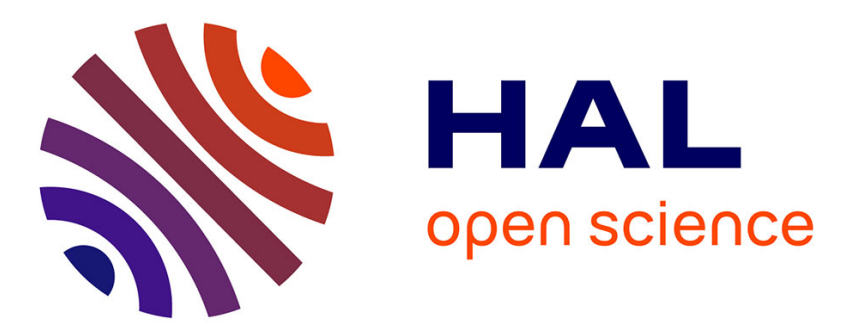

\title{
Diffusion of Palm Biodiesel in Elastomers Undergoing Multiaxial Large Deformations
}

\author{
Ch'ng Shiau Ying, Andri Andriyana, Erwan Verron, Roslina Ahmad
}

\section{To cite this version:}

Ch'ng Shiau Ying, Andri Andriyana, Erwan Verron, Roslina Ahmad. Diffusion of Palm Biodiesel in Elastomers Undergoing Multiaxial Large Deformations. Defect and Diffusion Forum (Online), 2013, 334-335, pp.77-82. 10.4028/www.scientific.net/DDF.334-335.77 . hal-03286771

\section{HAL Id: hal-03286771 \\ https://hal.science/hal-03286771}

Submitted on 28 Jul 2021

HAL is a multi-disciplinary open access archive for the deposit and dissemination of scientific research documents, whether they are published or not. The documents may come from teaching and research institutions in France or abroad, or from public or private research centers.
L'archive ouverte pluridisciplinaire HAL, est destinée au dépôt et à la diffusion de documents scientifiques de niveau recherche, publiés ou non, émanant des établissements d'enseignement et de recherche français ou étrangers, des laboratoires publics ou privés. 


\title{
Diffusion of Palm Biodiesel in Elastomers Undergoing Multiaxial Large Deformations
}

\author{
Ch'ng Shiau Ying ${ }^{1, a}$, Andri Andriyana ${ }^{1, b}$, Erwan Verron $^{2, c}$ \\ and Roslina Ahmad ${ }^{1, d}$ \\ ${ }^{1}$ Department of Mechanical Engineering, University of Malaya, 50603 Kuala Lumpur, Malaysia \\ ${ }^{2}$ LUNAM Université, École Centrale de Nantes, GeM, UMR CNRS 6183 \\ BP 92101, 44321 Nantes, France \\ ashiauying@siswa.um.edu.my, bandri.andriyana@um.edu.my, cerwan.verron@ec-nantes.fr, \\ droslina@um.edu.my
}

Keywords:Elastomer, palm biodiesel, swelling, multiaxial large strain, hydrostatic stress.

\begin{abstract}
Petroleum-based fuel is facing significant depletion issue due to its limited reserves and increasing demand from various industries. Thus, various considerations from economical, environmental and political concerns have motivated researchers to develop alternative energy sources such as biofuel to decrease dependence on petroleum-based fuel. However, the changes in the fuel composition of biofuel affect the material compatibility. In engineering applications where elastomeric components are exposed to hostile environment such as palm biodiesel medium, at least two aspects contribute to the degradation of the materials during the service: diffusion of the liquids leading to swelling and fluctuating multiaxial mechanical loading leading to fatigue failure. Therefore, it is of utmost importance to study the mechanical responses of elastomers under this coupled diffusion-mechanical loading in order to predict accurately their fatigue failure. The present work investigates the swelling of elastomers under simultaneous diffusion of palm biodiesel and multiaxial large deformations.
\end{abstract}

\section{Introduction}

The overwhelming global population growth and rapid industrialization have drastically increased the demand for petroleum-based fuel. However, considerations from environmental, political and economic factors motivate researchers to develop novel and renewable energy sources [1]. In this context, biofuel is gaining popularity but the particular chemical composition of biofuel affects significantly the performance of engineering components in particularly elastomeric parts such as seals, gaskets, pipes and O-rings. In engineering applications involving the contamination of potentially aggressive liquids such as palm biodiesel into elastomeric components, there are at least two important aspects which contribute to the degradation of the materials in service: diffusion of aggressive liquids leading to swelling and fluctuating multiaxial mechanical loading leading to fatigue failure. Indeed, the presence of solvent in the rubber matrix weakens the matrix and decreases its resistance to failure [2]. Hence, the understanding of interactions between the two phenomena is an essential pre-requisite for the durability analysis of such components.

Diffusion in elastomers had been extensively studied by Flory [3] and Treloar [4] who investigated the swelling instress-free rubber in solvents. Following these works, a number of studies are available in the literature dealing with the diffusion of liquids in elastomers undergoing uniaxial loading [5-12] and generally it was found that tensile stress increases swelling while opposite phenomenon is observed for compressive stress [6,13,14]. Treloar [4] attributed these phenomena to the hydrostatic part of the Cauchy stress in the materials. The author provided the same argument for the decrease in swelling of rubber cylinder undergoing simple torsion. It is important to highlight that in these works, the authors considered the diffusion for small strain problems only. The effect of large multiaxial deformation on the diffusion in elastomers is not established. 
The objective of the present work is to investigate the diffusion in elastomers under multiaxial large strain. For this purpose, simple experimental specimen and device are developed such that immersion tests can be conducted while the specimens are simultaneously subjected to various mechanical loadings: simple tension, simple torsion and combined tension-torsion.

\section{Experimental Program}

Materials. Specially designed elastomers are purchased from MAKA Engineering Sdn. Bhd., Malaysia. The as-received elastomeric specimens investigated in this paper are commercial grades of NBR and CR with 60 shore hardness and $25 \mathrm{wt} \%$ of carbon black content. Palm biodiesel is provided by Mission Biotechnologies Sdn. Bhd.All immersion tests are conducted in 100\% palm biodiesel at room temperature.

Experimental Device and Specimen. In order to investigate the diffusion of palm biodiesel into elastomers undergoing multiaxial large strain, specially-designed specimen and device are developed. They consist of a hollow diabolo elastomeric specimen equipped with circular metallic grips and plates as shown in Fig. 1.

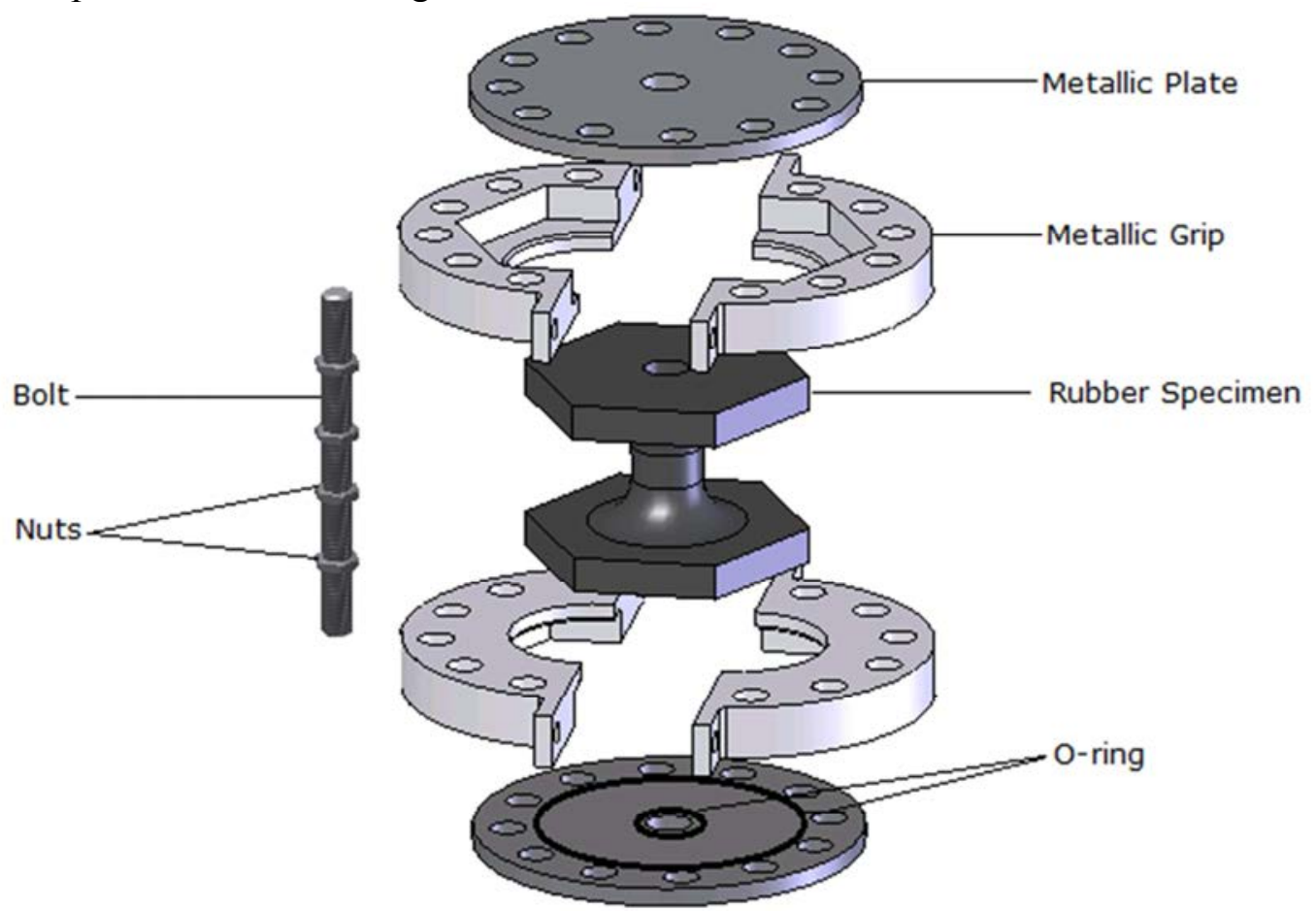

Fig. 1. Exploded view of the experimental device and specimen.

Immersion Testing and Swelling Measurement. In the present study, eight different mechanical loading conditions are investigated. The details of these conditions are given in Table 1 . The specimens are immersed in B100 for the duration of 1 week. To determine the swelling effect, the mass change of the specimens is measured after the immersion. The percentage of mass change is calculated using the following relation:

$$
\% \text { Masschange }=\frac{M_{2}-M_{1}}{M_{1}} \times 100
$$

where $M_{1}$ and $M_{2}$ are the mass before and after immersion. 
Table 1

Mechanical loading conditions.

\begin{tabular}{|l|c|c|c|c|}
\hline \multirow{2}{*}{ Specimen } & \multicolumn{4}{|c|}{ Applied Load } \\
\cline { 2 - 5 } & \multicolumn{2}{|c|}{ Tensile Load } & \multicolumn{2}{c|}{ Torsional Load } \\
\cline { 2 - 5 } & $\begin{array}{c}\text { Axial } \\
\text { extension } \\
\Delta \mathrm{L}(\mathrm{mm})\end{array}$ & $\begin{array}{c}\text { Resulting } \\
\text { stretch ratio } \\
\lambda=L / L_{o}\end{array}$ & $\begin{array}{c}\text { Twist angle } \\
\left({ }^{\circ}\right)\end{array}$ & $\begin{array}{c}\text { Resulting twist } \\
\text { per unit length } \\
\tau(\mathrm{rad} / \mathrm{mm})\end{array}$ \\
\hline S0 T0 & 0 & 1 & 0 & 0 \\
\hline S0 T30 & 0 & 1 & 30 & 0.02094 \\
\hline S0 T60 & 0 & 1 & 60 & 0.04189 \\
\hline S0 T90 & 0 & 1 & 90 & 0.06283 \\
\hline S20T0 & 5 & 1.2 & 0 & 0 \\
\hline S20T30 & 5 & 1.2 & 30 & 0.01745 \\
\hline S20T60 & 5 & 1.2 & 60 & 0.03491 \\
\hline S20T90 & 5 & 1.2 & 90 & 0.05236 \\
\hline
\end{tabular}

\section{Results and Discussion}

Swelling. Fig. 2 shows the percentage of mass change of NBR and CR immersed for one week in palm biodiesel under different loading conditions. For NBR, in the absence of tensile strain, the percentage of mass change varies from $1.4 \%$ to $1.9 \%$. Meanwhile, in the presence of tensile strain, the percentage of mass change ranges from $2.1 \%$ to $2.6 \%$. The percentage of mass change in CR ranges from $4.5 \%$ to $6.0 \%$ in the absence of tensile strain and from $7.0 \%$ to $7.8 \%$ in the presence of tensile strain. The effect of mechanical loading, in particularly tensile strain, on the amount of swelling is clearly shown in this Figure. It is observed that the application of $20 \%$ tensile strain to the rubber specimen increases the amount of liquid uptake by as much as $50 \%$ regardless the amount of applied twist. In contrast, the effect of twist on the swelling level appears to be not as significant as the effect of tensile strain.
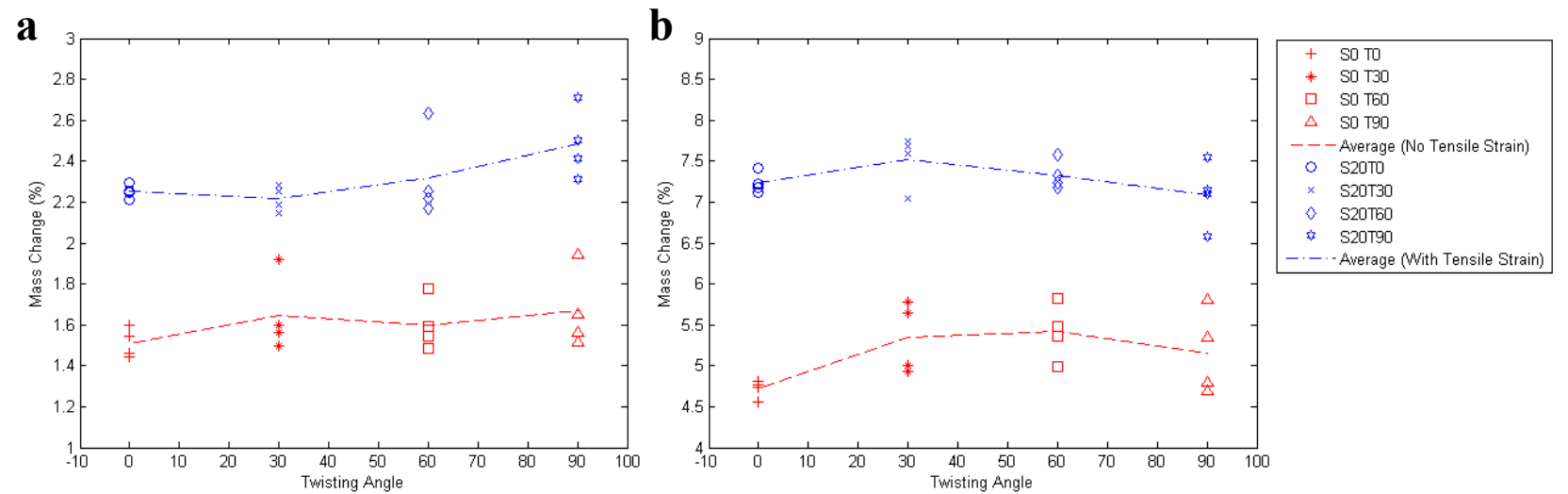

Fig. 2. Mass change of (a) NBR and (b) CR after 1 week immersion in palm biodiesel.

Mechanical Quantity Affecting Swelling Level. According to Treloar [4], the reduction or increase in the swelling is mainly governed by the hydrostatic part of the Cauchy stress. A tensile stress, for which the corresponding hydrostatic part is negative, leads to an increase in the swelling level and the opposite phenomenon is predicted for compressive stress. In the present study, complex mechanical loading conditions such as combined tension-torsion are addressed. Hence, the determination of the hydrostatic part of the Cauchy stress requires the analytical solution of hyperelastic hollow cylinder under corresponding mechanical loading conditions. 
The complete derivation of the governing equations for an isotropic incompressible hyperelastic tube under combined tension-torsion can be found for example in Green and Adkins [15], and with the present notations in [16] and [17].Using cylindrical coordinates system where $\left(\mathbf{e}_{\mathbf{r}}, \mathbf{e}_{\boldsymbol{\theta}}, \mathbf{e}_{\mathbf{z}}\right)$ represent the three unit vectors along radial, circumferential and axial directions respectively in the deformed configuration, for neo-Hookean constitutive equation, the resulting Cauchy stress tensor at any particular point of the undeformed configuration is given by:

$$
\begin{aligned}
\boldsymbol{\sigma}(R)= & C \lambda \tau^{2}\left(R^{2}-R_{0}^{2}\right) \boldsymbol{e}_{\boldsymbol{r}} \otimes \boldsymbol{e}_{\boldsymbol{r}}+C \lambda \tau^{2}\left(3 R^{2}-R_{0}^{2}\right) \boldsymbol{e}_{\boldsymbol{\theta}} \otimes \boldsymbol{e}_{\boldsymbol{\theta}}+2 C \lambda^{\frac{3}{2}} \tau R\left(\boldsymbol{e}_{\boldsymbol{\theta}} \otimes \boldsymbol{e}_{\mathbf{z}}+\boldsymbol{e}_{\mathbf{z}} \otimes \boldsymbol{e}_{\boldsymbol{\theta}}\right)+ \\
& {\left[2 C\left(\lambda^{2}-\frac{1}{\lambda}\right)+C \lambda \tau^{2}\left(R^{2}-R_{0}^{2}\right)\right] \boldsymbol{e}_{\mathbf{z}} \otimes \boldsymbol{e}_{\mathbf{z}} }
\end{aligned}
$$

where $\lambda$ is the stretch ratio and $\tau$ is the twist per unit length. For each loading condition, their values are tabulated in Table $1 . R$ is the radial position of any particular point in the undeformed configuration while $R_{o}$ is the initial outer radius of the cylinder. $C$ is the material parameter, identified from the first uploading stress response of the dry rubber. The hydrostatic stress is obtained by taking the trace of the Cauchy stress tensor [18]:

$$
p=-\frac{1}{3} \operatorname{tr}(\boldsymbol{\sigma})
$$

For each loading condition, the initial hydrostatic stress in the middle part of the specimen at various radial positions $R$ is calculated and depicted in Fig. 3 for both NBR and CR. For a given twist, it is observed that the hydrostatic stress decreases with the increase of radial position. More precisely, under torsion the elastomeric cylinder experiences compressive stress at the inner surface and tensile stress at the outer surface. There exists a particular plane along which the hydrostatic stress is zero. This particular plane is located at the critical radius $R_{c}=\sqrt{0.6} \cdot R_{O}$ and its location is independent of the applied twist. Between the inner surface and the particular plane, i.e. $R_{i}<$ $R<R_{c}$, the hydrostatic stress is positive (in compression state) while between the particular plane and the outer surface of the cylinder, i.e. $R>R_{c}$, the hydrostatic stress is negative (in tension state).
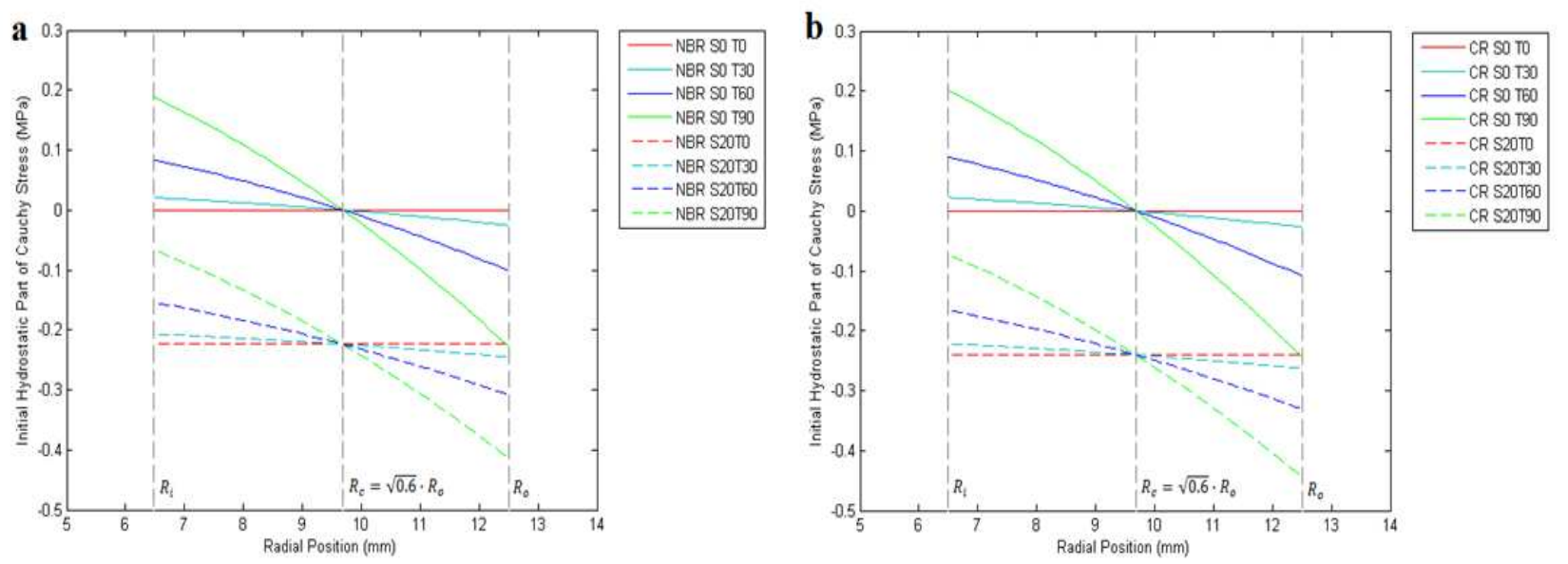

Fig. 3. Initial hydrostatic part of Cauchy stress at different radial position for (a) NBR and (b) CR.

Since the strain and stress are non-uniform in the rubber specimen, the average value of hydrostatic stress has to be calculated. Fig. 4 presents the average hydrostatic stress for different loading conditions. As shown in Fig. 4, the average value of hydrostatic stress does not change significantly with the increase of twist. Indeed, for the case of simple torsion, the average hydrostatic stresses in both NBR and CR are close to zero regardless the amount of twist. These results can be helpful in understanding why the swelling levels in our materials are not greatly affected by the amount of twist. 

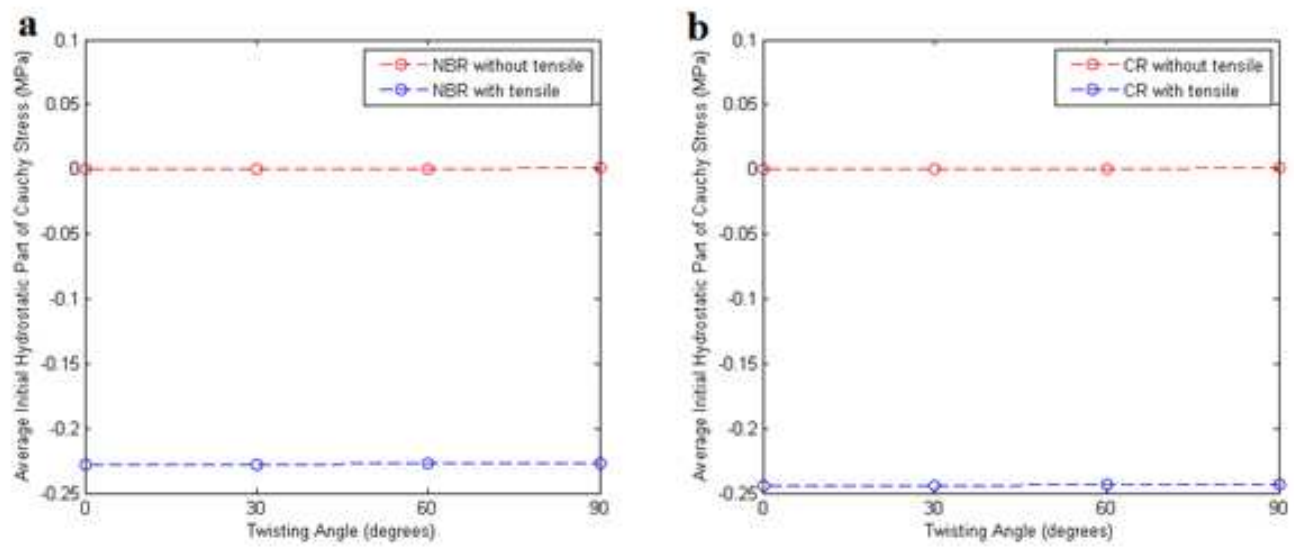

Fig. 4. Average initial hydrostatic part of Cauchy stress for (a) NBR and (b) CR.

In Fig. 5, the percentage of mass change is plotted against the average hydrostatic stress for different loading conditions. When twist is applied, it is found that the resulting swelling level is systematically higher than the swelling in stress-free specimens as shown in Figs. 5(a) and 9(c). The increase of swelling due to the application of twist is in contrast to the prediction of Treloar [14,19]. The corresponding discrepancy could be attributed to the geometry of the specimen. Indeed, while hollow cylindrical specimen is considered in the present study, Treloar used a solid cylindrical specimen. For a given twist, the zone of the cylinder experiencing compressive hydrostatic stress will be larger in the case of solid cylinder than that in the case of hollow cylinder. Since the zone having compressive hydrostatic stress is larger in the solid cylinder, the resulting average hydrostatic stress becomes higher. Thus, under a given twist, the resulting swelling in solid cylinder is lower than that in the hollow cylinder.
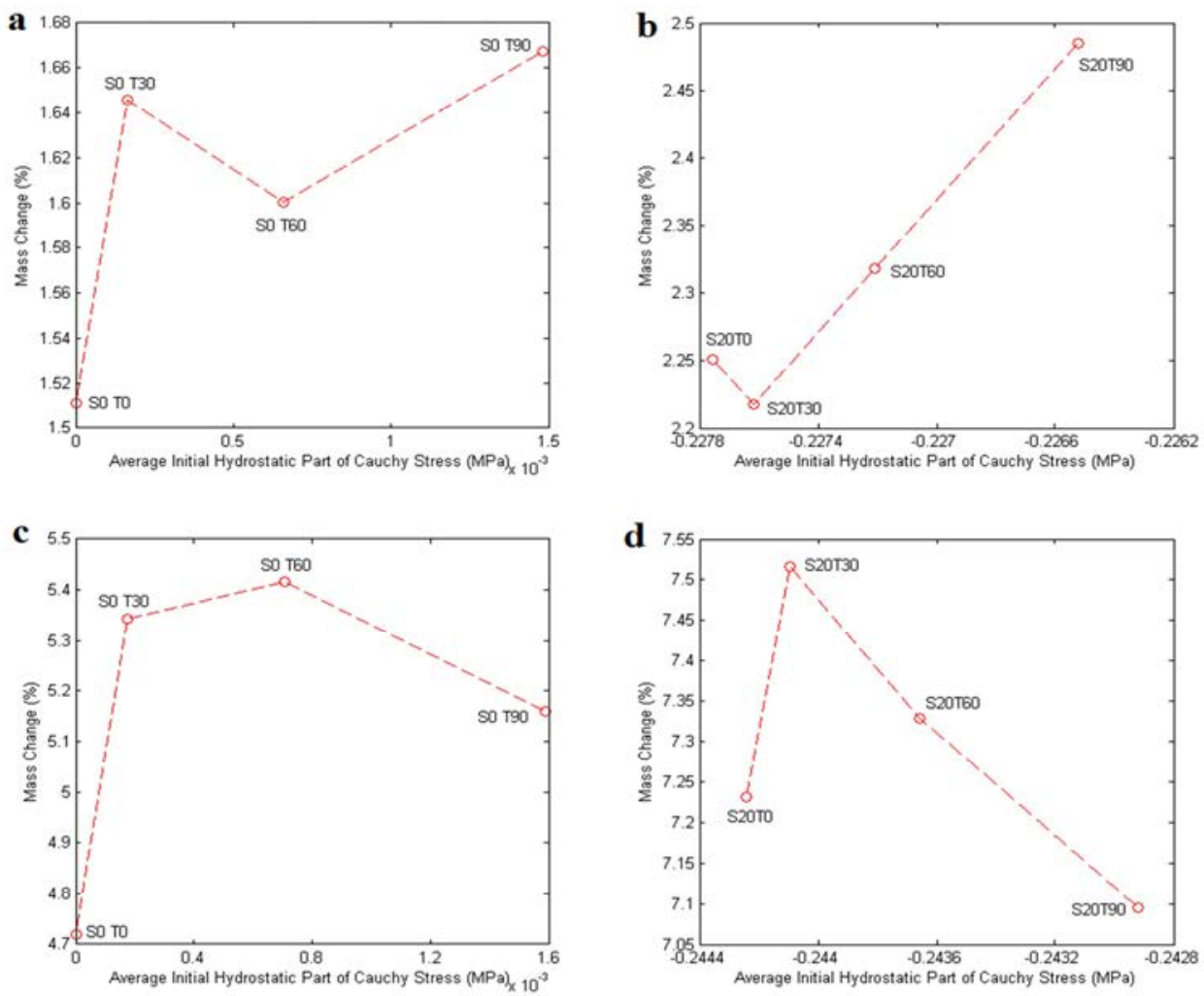

Fig. 5. Mass change as a function of average hydrostatic component of stress for (a) NBR without tensile strain, (b) NBR with tensile strain, (c) CR without tensile strain and (d) CR with tensile strain. 
Finally, the above observations suggest that the effect of torsion on swelling is dictated by the specimen geometry. For our purpose, a thin-walled cylinder with the above ratio would be preferable than the solid one since certain level of swelling can be reached within a relatively shorter period of time. Moreover, the resulting stress and strain fields will be relatively more uniform. Thus, in order to fully establish the effect of multiaxial loading on the swelling of elastomers, further works and validations using improved specimens with the condition $R_{i}>R_{c}$, which equivalent with the ratio $\frac{t}{R_{m}}<0.259$, where $t=R_{o}-R_{i}$ is the wall thickness and $R_{m}=$ $\frac{1}{2}\left(R_{o}+R_{i}\right)$ is the mean radius of the cylinder are required in the future.

\section{Conclusion}

The levels of swelling experienced by both NBR and CR are found to be significantly affected by the presence of mechanical loading. More precisely, the effect of tensile strain appeared to be more significant than that of torsion. It was found that the swelling level increases significantly when a tensile strain is introduced. Moreover, slight increase in swelling is observed when a twist is applied. The increase of swelling due to the application of torsion is in contrast to the observation of Treloar $[14,19]$. Our results suggest that the corresponding discrepancy could be attributed to the specimen geometry.

\section{Acknowledgements}

The authors greatly appreciate the financial support of the Ministry of Higher Education Malaysia through High Impact Research Grant MOHE-HIR D000008-16001.

\section{References}

[1] W. Trakarnpruk and S. Porntangjitlikit: Renewable Energy Vol. 33 (2008), p. 1558-1563

[2] K. Fukumori, T. Kurauchi and O. Kamigaito: Polymer Vol. 31 (1990), p. 2361-2367

[3] P.J. Flory: Principles of polymer chemistry (Cornell University Press, USA 1953).

[4] L.R.G. Treloar: The physics of rubber elasticity (Oxford University Press, USA 2005).

[5] S. Baek: International Journal of Non-Linear Mechanics Vol. 39 (2004), p. 201-218

[6] A.B. Chai, A. Andriyana, E. Verron, M.R. Johan and A.S.M.A. Haseeb: Polymer Testing Vol. 30 (2011), p. 867-875

[7] S.A. Chester and L. Anand: Journal of the Mechanics and Physics of Solids Vol. 58 (2010), p. 1879-1906

[8] M. Jerabek, Z. Major and R.W. Lang:Polymer Testing Vol. 29 (2010), p. 302-309

[9] J. Soares: International Journal of Engineering Science Vol. 47 (2009), p. 50-63

[10] S.L. Shenoy: Polymer Gels and Networks Vol. 6 (1998), p. 455-470

[11] W. Hong, X. Zhao, J. Zhou and Z. Suo: Journal of the Mechanics and Physics of Solids Vol. 56 (2008), p. 1779-1793

[12]K. Azaar, I.D. Rosca and J.M. Vergnaud: Polymer Vol. 43 (2002), p. 4261-4267

[13]A. Mostafa, A. Abouel-Kasem, M.R. Bayoumi and M.G. El-Sebaie: Materials \& Design Vol. 30 (2009), p. 1561-1568

[14]L. Treloar: Polymer Vol. 8 (1967), p. 433-442

[15]A.E. Green and J.E. Adkins: Large elastic deformations (Clarendon Press, Oxford 1970).

[16]A. Andriyana, N. Saintier and E. Verron: International Journal of Fatigue Vol. 32 (2010), p. $1627-1638$

[17]E. Verron and A. Andriyana: Journal of the Mechanics and Physics of Solids Vol. 56 (2008), p. 417-443

[18] G.A. Holzapfel: Nonlinear solid mechanics: a continuum approach for engineering (2000).

[19]L. Treloar: Polymer Vol. 13 (1972), p. 195-202 